\title{
How to achieve a win-win situation in colleges and universities to develop ethnic sports projects
}

\author{
Qiang Chen ${ }^{1,}$, Fang De Chen ${ }^{2, b}$ \\ ${ }^{1,2}$ Nanchang Institute of Science and Technology, P.E. Department; Nanchang, Jiangxi 330108 \\ a email, ${ }^{b}$ email
}

Key words: college sports; Ethnic sports; A win-win situation

\begin{abstract}
China is a multi-ethnic country, with the Han nationality population largest among the 56 ethnic groups. Except the Han nationality, the population of other ethnic groups is much less, and can be referred to as ethnic minorities. During the history development in our country, each nationality has its unique sports culture. At present, with the deepening of the reform of school physical education, the teaching road of socialism with Chinese characteristics has become the focus of teaching reform in colleges and universities. And homogeneity phenomenon of the ethnic minorities during the development of the society is more and more serious, therefore sports projects of ethnic minorities which have been passed down generation by generation is also facing the danger of extinction. Therefore, colleges and universities should carry out the ethnic minority sports projects, through which the students' nationality and patriotism consciousness can not only be enhanced, but also the college sports projects can be enriched, the comprehensive development of college students can be promoted. This article will be on how to develop ethnic minority sports projects in colleges and universities to achieve a win-win situation.
\end{abstract}

\section{Introduction}

The development of ethnic minority sports projects in colleges and universities makes the use of modern teaching conditions and teaching system to achieve the revitalization of ethnic minority sports projects. The ethnic minority sports projects carried out by universities not only retain and spread the traditional culture of ethnic minorities, but also enrich the teaching content of universities, and the learning of students.With the sports globalization promoted, the ethnic minority sports in our country has also been, to a great extent, developed, but in view of the current situation, because there is no enough attention paid to by the country, some problems still exist in the development of ethnic minority sports. The physical education of colleges and universities occupies an important position in China's sports development. Carrying out ethnic minority sports projects in colleges and universities can make up the shortcomings in the development of ethnic minority sports and, meanwhile, also make up the disadvantages of teaching in institutes of physical education in colleges and universities. The following will specifically explore the characteristics and functions of ethnic minority sports projects and the relationship between universities and ethnic minorities as well as strategies on how to achieve a win-win situation for the development of ethnic minority sports projects in colleges and universities.

\section{The characteristics and function of ethnic minority sports projects}

First, the forms of sports programs are diverse, rich and colorful. There are over 300 kinds of sports 
projects among China's various ethnic minorities, and from no matter which perspective, ethnic minority sports programs all show rich cultural content. Second, ethnic minority sports projects boasts of a long history and a profound origin. Many ethnic sports programs have a long tradition and a profound ethnic culture. And a lot of ethnic minority sports activities have their legends. Third, national sports activities are attached to the festivals, but their focus is on entertainment. Throughout our country's ethnic sports activities, a lot of them are carried out through the forms of games and theatrical performances, and these activities aim to entertain people.

The function of ethnic minority sports projects. First, the function of preserving culture. Ethnic sports represents a kind of culture of the whole nation, and also a kind of display to the ethnic character and preferences. And this cultural activity widely exists among the people, so it can be passed down. Second, the affinity function. In a nation a traditional ethnic sports custom can often attract the same nationality or the ethnic groups in the same area together, and form a natural recognition and affinity between them. Third, to strengthen the body. Sports activities have obvious physical fitness function. At the same time, by taking part in sports activities, it is also able to cultivate people's perseverance, willpower and team spirits.

\section{The relationship between the ethnic minority sports and college sports}

Colleges and universities provide opportunities for the development of ethnic minority sports. The ethnic minority sports programs evolve in the real life from the traditional sport forms. Some differences exist between ethnic sports forms and the modern college sports projects, so ethnic minority sports projects will be affected by its own ethnic economic, political and cultural factors in the development process. It carries the traditional ethnic culture, and bears a marked ethnic brand. But modern college students are hardly aware of the ethnic minority sports projects, with the ethnic assimilation having a negative impact on the development of ethnic sports projects. In order to better develop and preserve the ethnic culture in our country, the best way is to expand the education. Colleges and universities are an important base for cultivating a new generation of nation-building talents. College students are charged with an important duty of the inheritance of ethnic culture and national spirit. Carrying out ethnic minority sports projects in the colleges and universities can let more people understand them, and accordingly promote the development of ethnic minority sports programs.

The standardized management of college physical education promotes the development of ethnic minority sports. Colleges have high-quality teachers, students, rich information resources and comprehensive teaching system, as well as a strong economic foundation and standardized management, and these provide superior conditions for the development of ethnic minority sports projects. At present, some universities have carried out ethnic minority sports projects, and also set up a special professional team of teachers and research organizations. Researchers will study ethnic minority sports programs in ethnic minority residences, sort data and make in-depth study during this progress so as to provide scientific and technological support to the development of ethnic minority sports programs, and promote their deeper development.

The ethnic sports projects cultivate the student's ethnic culture emotion. In the reports of the 16th National Congress of the CPC, we have made it clear that the national spirit should be carried forward and cultivated . The ethnic spirits are the core content of the ethnic culture, and the ethnic culture is the value orientation of the ethnic spirits. Ethnic minority sports are the external manifestations of a national culture. Our country is now in the primary stage of socialism development, and hard-working, self-reliance, self-improvement of the excellent traditional spirits still need us to inherit. College students 
are the founder of a new generation of China's development, but they know little about ethnic sports culture. College students' lack of national spirit has serious adverse effects on the development of national culture in China. The development of ethnic sports in colleges and universities can increase the national cultural knowledge and national spirit of college students, and inherit and develop the national culture of our country.

Ethnic sports can stimulate students' interest in learning, and promote the construction of sports education of China's special characteristics. Ethnic sports show its value in colleges and universities through their characteristics in physical fitness, entertainment and sports performance. There are 56 ethnic groups in our country, the sports of all nationalities are developed through their life practice, so the sports programs of the ethnic minority culture is of diversity and richness, which bring greater development space for college sports, and the diversity of the forms and content makes up the simplicity of modern college sports, provides rich teaching contents for China's reform of college sports, also meet the requirement of students' learning, stimulate students interest in learning, improve student learning enthusiasm.

\section{A win-win strategy for ethnic minority sports projects in colleges and universities}

Colleges and universities should attach more importance to ethnic minority sports programs. Ethnic minority sports programs are the inheritance and development of ethnic culture. The leaders of colleges and universities should strengthen the attention on ethnic minority sports projects. To do so, first of all, we should increase research on minority sports projects, establish ethnic minority sports research institutions in colleges and universities, actively carry out research on ethnic minority sports teaching, and fully explore the culture and value of the minority sports. Secondly, more attention should be paid to the effective combination of ethnic minority sports and modern college sports. By analyzing and integrating, the ethnic minority sports programs is made scientific and standardized, and it can be adapted and integrated into the physical education in colleges and universities. Besides, in order to ensure the smooth development of ethnic minority sports, colleges and universities should also increase investment in sports venues construction and sports equipment purchases, at the same time, improve the rules of sports projects in the colleges and universities, to promote the standardization and systematization of physical education teaching in colleges and universities.

The carryout of ethnic minority sports teaching materials. Teaching materials are an important basis for teaching. At present, there are few textbooks about ethnic minority sports, although the minority sports programs are carried out in some colleges and universities, the process of teaching is only in the charge of individuals. The non-textbooks teaching will have a certain impact on the systematic and normative development of college sports programs, and thus affect the quality of the teaching of physical education in colleges and universities. Therefore, the development of ethnic minority sports in colleges and universities should be combined with the specific circumstances of colleges, be teaching-goal oriented, and the physical education teaching of colleges should be selectively developed and used.

Reasonable setting of college physical education curriculum. The effect of physical education teaching in colleges and universities will be influenced by teachers, students and teaching contents and so on. Some ethnic minority sports teaching may be unable to be completed in a certain period of time. At this time the actual situation of physical education teaching in colleges and universities should be combined with when setting and adjusting the college sports projects in order to achieve their positive development.

To create an ethnic minority sports culture atmosphere in colleges and universities. College campus sports culture is colleges' unique spiritual environment and cultural atmosphere. The ethnic minority 
sports projects promote the development of college physical education with its unique characteristics and functions. Therefore, when carrying out ethnic minority sports projects in the universities, an ethnic minority sports culture atmosphere should be created in the university campus in order to promote the smooth development of college ethnic minority sports projects. For example, setting up an ethnic minority sports association or club in colleges and universities can let students understand the ethnic minority sports and ethnic culture in their spare time and at the same time let students be trained. In addition, colleges and universities can also attract more students through the forms of sports competitions, so that the ethnic minority sports culture atmosphere in colleges and universities is stronger, and the development of the ethnic minority sports culture is better promoted.

Strengthening the training of the teachers of the ethnic minority sports. Teachers play a key role in the teaching process of the development of the ethnic minority sports in colleges and universities. But from the point of view of the physical education teachers in colleges and universities, the ethnic minority sports teachers are seriously inadequate. In order to smoothly develop ethnic minority sports projects in colleges and universities and ethnic culture, colleges and universities should actively introduce ethnic minority sports teachers, and at the same time strengthen the cultivation of professional teachers of the ethnic minority sports education. So colleges and universities must do a good job in teachers training of ethnic minority sports projects through organizing college physical education teachers to join ethnic minority sports projects activities, lectures, seminars and other forms of training, so that the training of physical education teachers in colleges and universities can be achieved, and,by this, improve their understanding and grasp of ethnic minority sports projects.

\section{Conclusion}

Ethnic minority sports are not only a sport or fitness activity, but also the embodiment of national culture. With the rapid development of society, ethnic groups are gradually assimilated, so the culture of a large number of ethnic minorities in China is partially facing the future of extinction . In order to preserve the ethnic culture and its development, to carry out the ethnic minority sports projects in colleges and universities is an effective way to inherit and develop the ethnic culture in our country. Modern sports in colleges and universities provide the conditions for the development of ethnic minority sports, while ethnic minority sports culture has made up for the shortcomings of modern physical education in China. In the teaching of physical education in colleges and universities, by strengthening the research construction of ethnic minority sports projects, increasing the number of teachers, exploring teaching materials and rationally allocating teaching courses, the development of ethnic minority sports programs can be prompted, meanwhile the development of modern colleges and universities sports can be promoted, and ultimately college sports education win-win objective can be achieved .

\section{References}

[1] Cao Yueyong. Of Guizhou 's Ethnic Traditional Sports and College Physical Education in Guizhou [J]. Tonghua Teachers College. 2012 (04)

[2] Tao traditional sports in colleges and universities to carry out the existing problems and countermeasures [J]. Chengdu Sport University. 2009 (08).

[3] Zhangshou Ping, Wang Tianjun. Minority Traditional Sports in College or University [J] is introduced. Sports Culture Guide, 2011 (07).

[4] Huang Ling, Wang Huiwen. Win Minority Sports Project [J] opened Universities. Southwest China 
Normal University (Natural Science), 2011 (06).

[5] Jiahong Gang, Mao Shiyu. Use [J] Minority Traditional Sports in College Physical Education. Border Economy and Culture, 2013 (02). 